\title{
Ovarian Papillary Tumor
}

National Cancer Institute

\section{Source}

National Cancer Institute. Ovarian Papillary Tumor. NCI Thesaurus. Code C8430.

A benign, borderline, or malignant epithelial tumor that arises from the ovary and is

characterized by the presence of papillary proliferations. Representative examples include surface papilloma, borderline serous surface papillary tumor, and serous surface papillary adenocarcinoma. 